\title{
Management of Priapism in Sickle Cell Patients: Experience of the Urology Department of the University Hospital Centre of Libreville
}

\author{
Adiren Mougougou1 ${ }^{*}$, Steevy Ndang Ngou Milama1, Jean Félix Ngomas², Natacha Boumas ${ }^{3}$, \\ Francine Chimelle Mbana Boukoulou', Dimitri Mbethe1, Izoudine Bissiriou1, \\ Jean Massande Mouyendi ${ }^{1}$ \\ ${ }^{1}$ Urology Department, University Hospital Center of Libreville, Libreville, Gabon \\ ${ }^{2}$ Emergency and Anaesthesia Department, University Hospital Center of Libreville, Libreville, Gabon \\ ${ }^{3}$ Paediatric Surgery Department, University Hospital Centre-Mother and Child-Jeanne Ebori Foundation, Libreville, Gabon \\ Email: *mougougouadrien@yahoo.fr
}

How to cite this paper: Mougougou, A., Ndang Ngou Milama, S., Ngomas, J.F., Boumas, N., Mbana Boukoulou, F.C., Mbethe, D., Bissiriou, I. and Massande Mouyendi, J. (2021) Management of Priapism in Sickle Cell Patients: Experience of the Urology Department of the University Hospital Centre of Libreville. Open Journal of Urology, 11, 87-94.

https://doi.org/10.4236/oju.2021.113009

Received: February 18, 2021

Accepted: March 27, 2021

Published: March 30, 2021

Copyright $\odot 2021$ by author(s) and Scientific Research Publishing Inc. This work is licensed under the Creative Commons Attribution International License (CC BY 4.0).

http://creativecommons.org/licenses/by/4.0/

\begin{abstract}
Introduction: Priapism is a rare pathology, known since antiquity. Sickle cell disease is the main aetiology in Africa. The aim of our work was to report our experience in its treatment. Material and Methods: This is a prospective, descriptive study carried out at the urology department of the Libreville University Hospital from January 2018 to December 2020. All sickle cell patients admitted to urology for priapism were included. The parameters studied were socio-demographic, clinical and therapeutic parameters as well as the evolution after treatment. Result: We collected 19 priapisms in sickle cell patients. The average age was 20.9 years with extremes of 4 and 53 years. Fifteen patients were homozygous SS. All patients had stasis priapism. The average consultation time was 22.4 hours. All patients had perioperative medical management combining hyperhydration, analgesia and antibiotic prophylaxis. A vasoactive drug was administered to 13 patients. Sixteen patients had a puncture of the corpus cavernosum. A distal cavernosal-spongiosum shunt under penile block was performed in 6 patients. The outcome was favorable from the outset in 12 cases, marked by complete detumescence of the corpus cavernosum. Partial detumescence was noted in 7 patients with the need for a new puncture of the cavernous body. A complication such as edema of the penis was in only one of our patients. A recurrence was noted in 2 patients. After an average follow-up of 6 months, no sequelae erectile dysfunction was observed. Conclusion: Priapism is a frequent complication among sickle cell patients in Libreville. Medical management associated with a cavernous puncture with administration of vasoactive drugs allows a favourable evolution without after-effects.
\end{abstract}




\section{Keywords}

Priapism, Sickle Cell Disease, Vasoactive Drug, Cavernous Puncture, Libreville

\section{Introduction}

Priapism is a rare condition, defined as an abnormally prolonged, often painful and irreducible erection occurring outside of sexual stimulation. It is a pathology known since ancient times. The term dates back to ancient Greece and derives from the god Priape [1]. Sickle cell disease is the major haematological cause of priapism in children and adults in Africa. It produces a picture of low-flow priapism linked to a slowing down of the cavernous circulation in connection with a cavernous drainage defect during the stiffening phase [2].

Indeed, the penis is an essentially vascular organ due to its penile corpus. Venous drainage takes place through the superficial and deep dorsal veins of the penis towards the pre-prostatic venous plexus [3]. During normal erection, there is a balance between the rigidity of the erectile bodies and venous drainage. Stasis priapism is thought to result from a blockage of the venous sinuses in the corpus cavernosum by pathological blockage of the detumescence mechanisms, thus prolonging the erection while the glans or spongy body remains flaccid [1].

The first-line treatment is medical, combining a puncture evacuating the cavernous blood and the intracavernous injection of alpha stimulants. The second-line treatment is surgical and consists of creating a cavernosal-spongiosum shunt. Among the various existing alpha-stimulating drugs, the use of etilefrin or phenylephrine is preferred because of their pure alpha-stimulating nature and better cardiovascular tolerance. The sometimes more readily available ephedrine can also be used. In the event of failure, of recurrence, or immediately in the event of suspicion of anoxia (pain, delay greater than 24 hours), the gas measurement of the cavernous blood is indicated to assess the intensity of the anoxic suffering and indicate the time of surgery [2]. Several authors [3] [4] [5] report the use of these drugs with varying results.

In addition to the treatment of priapism, it seems essential to us to insist on the classic treatment of a vaso-occlusive crisis in this sickle cell area.

The functional prognosis of the patient is related to the delay in the treatment of priapism with the fear of a definitive erectile dysfunction due to fibrosis of the corpus cavernosum. Priapism represents a major andrological emergency.

The aim of this work is to study strategies for the management of priapism in sickle cell patients in the urology department of the Libreville University Hospital Centre (CHUL) and to assess any complications.

\section{Materials and Methods}

This is a prospective study carried out in the urology department of the CHUL 
from January 2018 to December 2020. All patients with sickle cell disease admitted to urology for the treatment of priapism were included. Four patients lost to follow-up after hospitalization were excluded from the study. Priapisms in non-sickle cell disease were not included. The data was collected from a survey form including the following parameters:

- Socio-demographic (surname, first names, age, profession).

- Diagnosis (presence of a prolonged, painful, irreducible erection, haemoglobin electrophoresis, number of episodes of priapism, delay in treatment, existence or not of associated factors).

- Therapeutic (medical, instrumental or surgical).

\section{* Drug treatment}

- Rehydration with crystalloids.

- Paracetamol analgesia-Nefopam-Tramadol for adults or Paracetamol-Morniflumate for children.

- Antibioprophylaxis with Cefuroxime.

- Oral alpha stimulants with close monitoring of blood pressure: etilefrine hydrochloride or heptaminol hydrochloride.

\section{* Instrumental treatment}

Usually unilateral because of the communication between the two corpus cavernosum, this was an evacuating puncture combined with a corpus cavernosum wash (PCC) under local anaesthesia (penile block) or general anaesthesia with laryngeal mask in children. We performed a longitudinal or lateral PCC using a large catheter $(16$ or $18 \mathrm{G})$. The evacuation continued until the result was bright red, fluid blood, then washed with a few millilitres of physiological saline combined with an intracavernous injection (IIC) of vasoactive substances (alpha stimulants which promote the contraction of the corpus cavernosum). We used epinephrine (Adrénaline ${ }^{\circledast}$ ) with a dilution of $1 \mathrm{mg} / \mathrm{l}$ of saline, followed by a compressive dressing of the penis to avoid a haematoma.

\section{Surgical treatment}

The principle consists of draining a high-pressure system (cavernous body) to a lowpressure system (spongy body). We used the distal cavernosal-songiosum shunt or T-shunt according to the Al Ghorab technique under local-regional anaesthesia (penile block) or general anaesthesia in the operating theatre.

Progressive monitoring noted detumescence, length of hospitalisation, possible complications.

The purely clinical diagnosis was made on an emergency basis by a resident doctor or intern. No further examination was required.

This care was gradual, depending on the consultation period and the evolving response after each stage.

\section{* Data processing}

The data collected was entered and analyzed using Excel software.

\section{Ethical and legal aspects}

All the patients included in the study had given their informed consent (that 
of the legal representative for minor patients). We also received authorization from the medical affairs department of the $\mathrm{CHU}$ to conduct this study.

However, the data sheets were secured within the department and only team members had access to the data. All members had signed a confidentiality clause.

\section{Results}

We received 19 priapisms in sickle cell patients out of 1183 patients hospitalised during the study period, i.e. a prevalence of $1.6 \%$. The average age was 20.9 years with extremes of 4 and 53 years. Of these 19 patients, 15 (78.9\%) were homozygous SS sickle cell patients, 3 were heterozygous AS and 1 patient was heterozygous SC. All patients had stasis priapism. The average consultation time was 22.4 hours with extremes of 5 and 76 hours. It should be noted that 9 patients had consulted after 24 hours. We noted that erectile tissue was taken in 4 cases, including 3 heterozygous AS patients. No intracavernous injection or penile trauma was observed.

Therapeutically, all the patients had benefited from perioperative medical care combining hyperhydration, analgesia and antibiotic prophylaxis. Only 13 patients had received oral administration of vasoactive substances (etilefrin hydrochloride in 10 cases at a dose of 25 to $100 \mathrm{mg} / 24$ hours and heptaminol hydrochloride in 3 cases). Due to the lack of availability of these drugs in pharmacies, 6 patients were not able to benefit from them. A corpus cavernosumpuncture was carried out in 16 patients. Intracavernosal injection of adrenaline diluted with saline was only performed in 7 cases. A posthectomy was associated in 2 cases. We performed a distal cavernosal-spongiosum shunt according to the $\mathrm{Al}$ Ghorab technique under penile block in 6 patients, 3 of which were directly before a very late consultation.

The majority of the patients had benefited from drug treatment combined with instrumental or surgical treatment. Only one 7-year-old patient who consulted within 6 hours had only benefited from medical treatment with a favourable evolution (complete detumescence).

The average length of hospitalisation for patients was 4.6 days with extremes of 1 and 13 days. The evolution of patients summarized in Figure 1 was immediately favourable in 12 cases marked by a complete detumescence of the corpus cavernosum. We noted partial detumescence in 7 patients with the need for a new puncture of the corpus cavernosum associated with a reinjection of alpha stimulant in 4 cases. Three patients had benefited from a caverno-cancellous shunt due to an unfavourable evolution after the cavernous puncture.

The evolution was marked by the occurrence of complications such as edema of the penis in a patient whose anti-oedematous treatment allowed regression after 48 hours. A recurrence was noted in 2 patients one and 8 months after the previous episode. After an average follow-up of 6 months, no sequellaire erectile dysfunction was observed. 


\section{Number of patients}

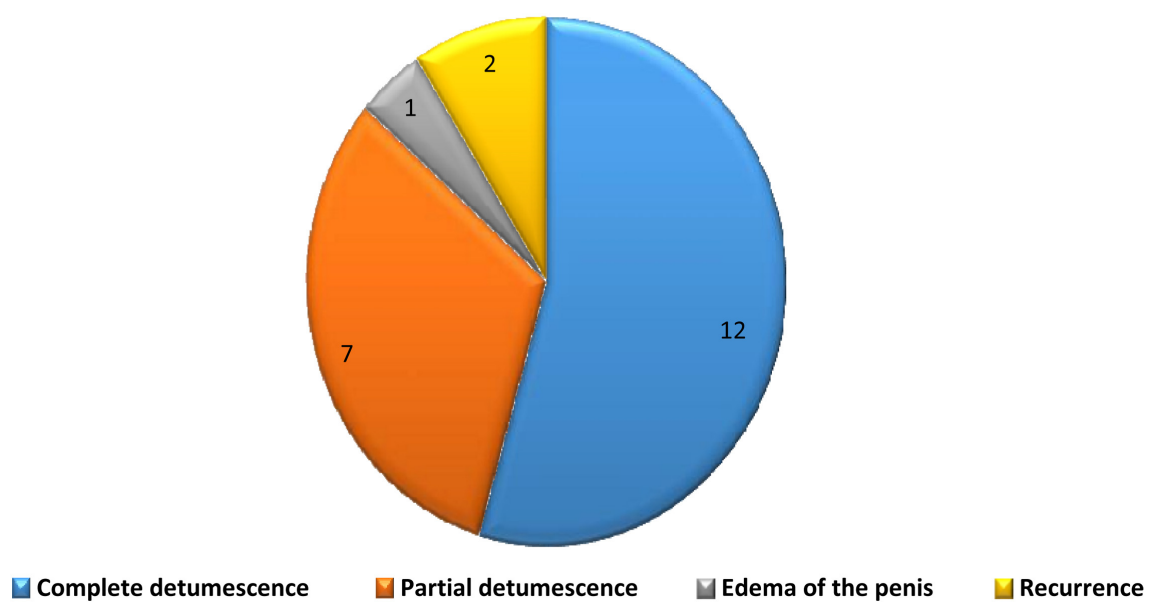

Figure 1. Progress data of patients treated for priapism and sickle cell disease at the university hospital of Libreville from 2018 to 2020.

\section{Limitations of the Study}

Although this prospective study has limitations, particularly in relation to:

- the sample: the number of patients does not reflect the reality of the problem. We believe that many patients are not well oriented;

- the difficulty of carrying out additional emergency examinations, in particular hemoglobin electrophoresis (due to lack of financial resources) in order to establish a definitive diagnosis and adequate management for the patient;

- the absence of blood gases and the frequent unavailability of certain drugs which could affect the results of the treatment;

- patients lost to follow-up after emergency treatment. Thus, the definitive diagnosis and treatment could not be evaluated in these patients;

- the lack of funding for the study, which would have made it possible to quickly carry out paraclinical examinations and the purchase of certain drugs.

Despite these limitations, the main epidemiological, clinical and therapeutic aspects allow us to make assessments compared to the data in the literature. The informations represent a first mapping of the specific management of this urgent pathology in this particular field in our country.

\section{Discussion and Comments}

Priapism is a very rare pathology. Sickle cell disease, an endemic pathology, plays a leading role among the aetiologies. Patients affected by this pathology are particularly exposed to the risk of priapism. At least $40 \%$ of sickle cell patients report episodes of priapism [4].

We have a fairly large number of cases over a short study period in a relatively young population. These results are the same on those of Moby Mpah et al. [5] in Cameroon, who report 33 cases of priapism, 19 of which were in sickle cell patients over a period of 36 months. In a prospective study conducted over 7 
months in Congo, Okoko et al. [6] reported a larger sample of 68 cases of priapism in sickle cell patients, but in $79.4 \%$ of cases it was intermittent priapism which did not require hospital care. They are higher than those of Falandry et al. [1] in 4 black African countries, including Gabon, where 19 cases of priapism from all causes were reported in 18 years. They are more distant from those of the team in Tunisia [7] where the population is older (average age 43 years) and the aetiology of sickle cell disease is less frequent. Over a longer period (11 years), Bouya et al. [8] reported 32 cases of sickle cell priapism representing $62.5 \%$ of the priapisms treated in the urology department, with the age of the patients varying from 7 to 32 years, with an average of 15.5 years.

The low prevalence of our series could be justified by the fact that it relates to all patients hospitalised during the study period. It is thus similar to a broader reflection of the pathology in the general population, whereas it is calculated by several authors [4] [6] [7] [8] on a sample of sickle cell patients or priapisms, whatever the aetiology. This disparity is confirmed by Arduini et al. [9] in a compilation of 13 articles, including 6 African articles on the prevalence and characteristics of priapism in sickle-cell sufferers. These authors report an age ranging from 7 to 30 years and a prevalence of $0.67 \%$ to $48 \%$. They believe that the prevalence of priapism is not real and explanations include under-reporting by patients, lack of awareness among doctors and lack of appropriate prospective studies.

In our series, the treatment time for sickle cell priapism was greater than or equal to 5 hours with an average of 22.4 hours. These data can be compared with those of Bouya et al. [8] in Congo, who report a consultation time of 6 to 48 hours. This is better than the 4-day delay reported by Falandry et al. [1] in their cross-border study as well as those of Fall et al. [10] in Senegal and Okoko et al. [6] in Congo who note that more than $80 \%$ of patients had consulted more than 24 hours. This could be explained by the multidisciplinary collaboration (paediatrics-haematology-urology) in the management of sickle cell disease and its complications. However, this consultation period is still long and improving it requires education and awareness raising actions for patients and their families as well as for health personnel, because according to Carnicelli and Akakpo [11], this is an emergency treatment whose aim is to prevent irreversible erectile dysfunction. The duration of the priapism and the delay in treatment are predictive factors for the recovery of erectile function. Histological changes are observed as early as the 12th hour and, in extreme cases, a necrosis of the smooth muscle after 48 hours [11].

All patients had stasis priapism. Among them, 15 patients (78.9\%) were homozygous SS. This result is in line with the data in the literature, which shows a predominance of homozygous SS sickle cell disease in $70 \%$ to $100 \%$ of cases [8] [9] [10]. Sickle-cell anaemia is a frequent cause of priapism with more than a third of patients (homozygous SS) presenting at least one episode of priapism [11]. The mechanisms causing priapism in this group of patients are varied and incompletely elucidated, but are probably linked to a lack of regulation of nitric 
oxide (NO) and phosphodiesterase type 5 enzyme activity [11].

The diagnosis of priapism is clinical (pain and rigidity of the penis). Additional examinations help to define the type of priapism and to support the etiological diagnosis. The diagnosis of ischaemic priapism can be made on the basis of an examination of the cavernous blood gases. This assessment is completed by a blood count and platelet count as well as a haemostasis assessment and, depending on the clinical context, by a chest X-ray and an abdomino-pelvic CT scan. Doppler ultrasound of the penis and the perineum is also performed in case of arterial priapism in order to highlight the site of the fistula. Finally, magnetic resonance imaging of the penis, which is not routinely required, can be discussed for predictive purposes to assess muscle viability [11]. In our series, the diagnosis was clinical because the majority of patients were known to have sickle cell disease.

Therapeutically, all the patients had received drug treatment. This medical treatment is poorly used by several authors [5] [8] [10] [12]. Our attitude is in line with that of Carniceli and Akakpo [11] who state that in the case of priapism in a sickle cell patient, local treatment of the priapism will be associated with general measures including hydration and intravenous analgesics, oxygen therapy and possibly plasma exchanges. In 16 cases $(84.2 \%)$ a puncture of the corpus cavernosum and/or a distal cavernosal-spongiosum shunt according to $\mathrm{Al}$ Ghorab in 6 cases were associated with the treatment. Corpus cavernosum puncture is widely practised by Kassogue et al. [4] in Mali, Moby Mpah et al. [5] in Cameroon and Fall et al. [10] in Senegal in 89\%, 67.9\% and 52.4\% of cases respectively. However, several series [3] [8] [12] reveal that surgical management was necessary in the majority of cases. This took place after failure of medical treatment or puncture of the corpus cavernosum. The lower use of surgery in our study could be explained by the relatively short average treatment time for priapism on the one hand, but also by the systematic combination of drug treatment before, during and after corpus cavernosum puncture on the other hand. Our practice is in line with the recommendations in the literature, which indicate that the first specialised therapeutic step consists of puncture-drainage of the corpus cavernosum with a 19 gauge needle (after local anaesthesia or penile block) at the lateral edge of the penis. A gentle suction can be performed until red blood is obtained. This treatment can be completed with an intracavernous injection of alpha-adrenergic agonists such as phenylephrine or etilephrine. Phenylephrine is usually diluted in physiological saline to obtain a concentration between 100 and $500 \mu \mathrm{g} / \mathrm{mL}$. An injection of $1 \mathrm{~mL}$ will be given every 3 to 5 minutes for 1 hour under tension control without exceeding $1 \mathrm{mg}$. A finer needle of 25 to 30 gauge may be used [11].

The evolution was favourable from the outset, marked by complete detumescence in $63.2 \%$ of cases and no fibrosis was observed after an average decline of 6 months. This development was better than that of several authors [3] [5] [10] [12] who report an absence of erection in $14 \%$ to $38 \%$ of cases. This result is cer- 
tainly linked to the important role of medical treatment, which is indispensable in sickle cell crises.

\section{Conclusion}

Priapism is a frequent complication for sickle cell patients in Libreville. Medical management of a sickle cell crisis associated with a corpus cavernosum puncture with perioperative administration of vasoactive drugs allows a favourable evolution without sequelae. The consultation times remain long. Raising awareness of the population, sickle cell patients and health personnel about this pathology will help to limit its dramatic consequences.

\section{Conflicts of Interest}

The authors declare no conflicts of interest regarding the publication of this paper.

\section{References}

[1] Falandry, L., Berlizot, P., Fournier, R., et al. (2000) Traitement chirurgical du priapisme: Expérience de 56 cas en milieu africain. Médecine Tropicale, 60, 70-74.

[2] Droupy, S. and Giuliano, F. (2013) Priapismes. Progrès en Urologie, 23, 638-646. https://doi.org/10.1016/j.purol.2013.01.026

[3] Nandiolo-Anelone, K.R., Djè, K., Bankolé, S.R., et al. (2011) Prise en charge du priapisme chez l'enfant au CHU de Treichville. African Journal of Urology, 17, 59-65. https://doi.org/10.1007/s12301-011-0012-4

[4] Kassogué, A., Coulibaly, M., Ouattara, Z., et al. (2014) Aspects cliniques et thérapeutiques du priapisme au CHU Gabriel Touré: étude de 36 cas. Pan African Medical Journal, 17, 286. https://doi.org/10.11604/pamj.2014.17.286.4109

[5] Bouya, P.A., Odzebé, A.W.S., Koumou, R.D., et al. (2011) Priapisme aigu drépanocytaire: Analyse de 20 cas traités au CHU de Brazzaville. Basic and Clinical Andrology, 21, 34-37. https://doi.org/10.1007/s12610-010-0110-3

[6] Moby Mpah, E.H., Fouda, P.J., Sal-Beyeme, T., et al. (2012) Les urgences andrologiques en milieu urbain au Cameroun: Aspects cliniques et thérapeutiques. Andrologie, 22, 223-226. https://doi.org/10.1007/s12610-012-0190-3

[7] Okoko, A.R., Odzébé, A.W.S., Moyen, E., et al. (2014) Priapisme chez l'enfant et l'adolescent drépanocytaire homozygote à Brazzaville. Progrès en Urologie, 24, 57-61. https://doi.org/10.1016/j.purol.2013.04.021

[8] Kamel, K., Mohamed, M., Abderrazek, B., et al. (2016) Prise en charge du priapisme à bas débit vu tardivement: À propos de 28 cas. African Journal of Urology, 22, 297-304. https://doi.org/10.1016/j.afju.2015.10.005

[9] Arduini, G.A.O. and Trovó de Marqui, A.B. (2018) Prevalence and Characteristics of Priapism in Sickle Cell Disease. Hemoglobin, 42, 73-77. https://doi.org/10.1080/03630269.2018.1452760

[10] Fall, P.A., Dia, B., Ndoye, A.K., et al. (2005) Le priapisme : particularités cliniques et étiologiques. African Journal of Urology, 11, 186-190.

[11] Carnicelli, D. and Akakpo, W. (2018) Le priapisme: Diagnostic et prise en charge. Progrès en Urologie, 14, 772-776. https://doi.org/10.1016/j.purol.2018.07.281

[12] Kouame, B., Gbeli, F.M., Kramo, F., et al. (2018) Urgences péniennes: Caractéristiques épidémiologiques, lésionnelles et évolutives. Uro'Andro, 9, 442-446. 